\title{
Adsorption and Diffusion of Carbon Dioxide, Methane, and Their Mixture in Carbon Nanotubes in the Presence of Water
}

\author{
Yafan Yang, Arun Kumar Narayanan Nair* and Shuyu Sun ${ }^{\dagger}$ \\ Physical Science and Engineering Division (PSE), \\ Computational Transport Phenomena Laboratory, \\ King Abdullah University of Science and Technology (KAUST), \\ Thuwal, 23955-6900, Saudi Arabia.
}

July 9, 2020

\footnotetext{
*To whom correspondence should be addressed, email: arun.narayanannair@kaust.edu.sa

${ }^{\dagger}$ To whom correspondence should be addressed, email: shuyu.sun@kaust.edu.sa 


\begin{abstract}
Molecular simulations were performed to investigate the adsorption and diffusion properties of methane and carbon dioxide in carbon nanotubes (CNTs) with preadsorbed water at $300 \mathrm{~K}$ and pressures up to 40 bar. Our results show that, at low pressures, a high uptake of methane and carbon dioxide is obtained in relatively small pores, and the presence of water enhances the adsorption of carbon dioxide in CNTs with large diameters. The effect of the preadsorbed water is more pronounced on the mobility of methane than that of carbon dioxide. Importantly, at high water contents, we see that the mobility of methane is a nonmonotonic function of the nanotube diameter. This is probably due to the splitting of the water clusters in the small pores which may lead to a faster diffusion process. Simulations were also performed for the methane/carbon dioxide mixture in CNTs with preadsorbed water. Here, the overall adsorption and diffusion properties are similar to those observed for the methane/water and carbon dioxide/water mixtures in CNTs. The adsorption selectivity of carbon dioxide over methane increases with water content which may be because of the relatively stronger water-carbon dioxide interactions. A significant result is that the mobility of methane in the CNTs decreases with decreasing bulk mole fraction of methane. In general, this decrease is more pronounced at higher loadings of methane and lower water contents. However, the presence of methane has less effect on the diffusion properties of carbon dioxide in the CNTs. These results may be explained by the preferential adsorption of carbon dioxide over methane in the CNTs. Furthermore, these simulated adsorption isotherms and diffusivity results are in reasonable agreement with the theoretical predictions based on the ideal adsorbed solution theory and the Krishna and Paschek approach, respectively.
\end{abstract}




\section{Introduction}

The important parameters for gas storage and separation are the permeability of a specific species of the gas mixture and the selectivity. ${ }^{1-7}$ Notably, the separation processes can be adjusted by tuning the adsorption and/or diffusion selectivities. For example, the silica zeolite DDR has adsorption selectivity of $\sim 4$ and diffusion selectivity $>100$ for equimolar $\mathrm{CO}_{2} / \mathrm{CH}_{4}$ mixture at room temperature. ${ }^{4}$ Usually membranes with a high permeability and a high selectivity are suitable for commercial applications. According to the Robeson plot, ${ }^{8}$ the selectivity of the membranes generally decreases with increasing permeability. Therefore, studies are being conducted to surpass the Robeson upper bound of polymer membranes by designing new materials. These materials include, but are not limited to, metal-organic frameworks, zeolites, and carbon nanotubes (CNTs). Today, such materials find applications in capturing the greenhouse gas carbon dioxide, commercial demands for hydrogen storage, storage of natural gas, etc. ${ }^{9-17}$ Notably, because of their exceptional properties such as high mechanical strength, large specific surface area, high aspect ratio, and relatively low cost, CNTs are excellent candidates for gas storage and separation processes. ${ }^{12-17}$

There have been extensive studies on the adsorption ${ }^{12-15,18-23}$ and diffusion ${ }^{7,19,24,25}$ properties of $\mathrm{CH}_{4}$ and $\mathrm{CO}_{2}$ in CNTs. These studies showed that, at low pressures, a high uptake of $\mathrm{CH}_{4}$ and $\mathrm{CO}_{2}$ is achieved in relatively small pores, which can be attributed to the fluid-solid interaction. Liu et al. studied the adsorption and diffusion properties of $\mathrm{CH}_{4}$ and $\mathrm{CO}_{2}$ in the CNTs in the presence of water. ${ }^{22-24}$ At low pressures, the presence of $\mathrm{H}_{2} \mathrm{O}$ enhanced the adsorption of $\mathrm{CO}_{2}$ in CNTs with large diameters, which was attributed to the $\mathrm{CO}_{2}$-water interaction. It was found that because of their strong $\mathrm{H}$-bonding, $\mathrm{H}_{2} \mathrm{O}$ molecules transport in the form of clusters and block the diffusion of $\mathrm{CH}_{4}$. There have been many studies on the adsorption properties of the $\mathrm{CH}_{4} / \mathrm{CO}_{2}$ mixture in the CNTs. ${ }^{20,22,26,27}$ These studies showed that the adsorption selectivity of $\mathrm{CO}_{2}$ over $\mathrm{CH}_{4}$ generally increases with pressure, which may be attributed to the fluid-fluid interaction. Liu et al. also studied the adsorption properties of the 
$\mathrm{CH}_{4} / \mathrm{CO}_{2}$ mixture in the CNTs in the presence of water. ${ }^{22}$ They showed that the adsorption selectivity of $\mathrm{CO}_{2}$ over $\mathrm{CH}_{4}$ increases with water content which may be attributed to the relatively stronger water- $\mathrm{CO}_{2}$ interactions. However, a molecularlevel understanding of the diffusion properties of the $\mathrm{CH}_{4} / \mathrm{CO}_{2}$ mixture in the CNTs in the presence of water is lacking.

Molecular simulations offer detailed molecular-level picture of the interactions between the components in different systems. ${ }^{28-32}$ In this study, molecular simulations were performed to investigate the adsorption and diffusion properties of $\mathrm{CH}_{4}, \mathrm{CO}_{2}$, and their mixture in single-walled CNT arrays with preadsorbed water at $300 \mathrm{~K}$ and pressures up to 40 bar. In addition, the current simulation study was complemented by theoretical calculations because of the lack of experimental data, especially for the $\mathrm{CH}_{4} / \mathrm{CO}_{2} / \mathrm{H}_{2} \mathrm{O}$ mixture in the CNTs.

\section{Simulation details}

Molecular simulations were performed to investigate the adsorption and diffusion properties of $\mathrm{CH}_{4}, \mathrm{CO}_{2}$, and their mixture in single-walled CNT arrays with preadsorbed water at $300 \mathrm{~K}$ and pressures up to 40 bar. The simulation models and methods used here are generally similar to those reported in our previous work. ${ }^{33-41}$ We used the GCMC simulation technique to calculate the adsorption isotherms and the MD simulation technique was employed to predict the dynamic properties. The GCMC and MD simulations were carried out using the RASPA ${ }^{42}$ and LAMMPS ${ }^{43}$ packages, respectively. The $(7,7),(10,10)$, and $(15,15)$ nanotubes with diameters of $0.950,1.356$, and $2.030 \mathrm{~nm}$, respectively, were employed, and the intertube distance (surface-to-surface) was set to $0.335 \mathrm{~nm}$ in all cases (Fig. 1). As in previous studies, ${ }^{22,24}$ the nanotubes are loaded with different amounts of preadsorbed water $\left(0,0.05,0.1\right.$, and $\left.0.2 \mathrm{~g} / \mathrm{cm}^{3}\right)$. For simplicity, no water is included in the interstitial region. The simulation box dimensions were $2.57 \times 4.45 \times 6.39,2.93 \times 3.38 \times 6.39$, and $2.37 \times 4.10 \times 6.39 \mathrm{~nm}^{3}$, for the $(7,7),(10,10)$, and $(15,15)$ nanotubes, respectively. The framework is held rigid 
during the simulations and the Lennard-Jones (LJ) 12-6 potential parameters for the framework carbon atoms were taken from Steele. ${ }^{44}$ Water was modeled using the rigid SPC/E model, ${ }^{45}$ and $\mathrm{CH}_{4}$ (single-site) and $\mathrm{CO}_{2}$ were represented by the transferable potentials for phase equilibria (TraPPE) ${ }^{46}$ and EPM2 force fields, respectively. ${ }^{47}$ However, note that a flexible version of the EPM2 $2^{48}$ force field for $\mathrm{CO}_{2}$ was employed in our MD simulations. The LJ parameters between unlike atoms are calculated by the standard Lorentz-Berthelot combining rule. Periodic boundary conditions were applied in all three dimensions. The long-range Coulombic interactions were calculated using the Ewald summation (GCMC) and the particle-particle particle-mesh (MD) techniques with a precision of $10^{-5}$. The nonbonded cutoff was set to $1.15 \mathrm{~nm}$.

In the GCMC simulations, the sorbate molecules $\left(\mathrm{CH}_{4}\right.$ and $\left.\mathrm{CO}_{2}\right)$ were allowed to move in and out of the simulation box, while keeping the number of preadsorbed water molecules constant. Each GCMC simulation comprised of at least $10^{7}$ Monte Carlo steps. The isosteric heat of adsorption $q_{\mathrm{st}}$ is estimated using the equation proposed by Karavias and Myers: ${ }^{49}$

$$
q_{\mathrm{st}}=-\left(h^{\mathrm{b}, *}-h^{\mathrm{b}}\right)+R T-\frac{\langle U N\rangle-\langle U\rangle\langle N\rangle}{\left\langle N^{2}\right\rangle-\langle N\rangle^{2}},
$$

where $-\left(h^{\mathrm{b}, *}-h^{\mathrm{b}}\right)$ is the departure function for the partial molar enthalpy in the bulk fluid and it is calculated from the Peng-Robinson equation of state. ${ }^{50} U$ and $N$ are the energy of the adsorbed phase and the number of adsorbed molecules, respectively, and the angle brackets denote the averages in the GCMC simulations.

Furthermore, the final configurations from the GCMC simulations were used as the starting configurations for the MD simulations. The MD simulations are carried out in the NVT ensemble. The equations of motion are integrated with a velocity Verlet method and a time step of 1 fs. A Langevin thermostat was used with a damping coefficient of $1 \mathrm{ps}^{-1} .{ }^{51}$ The implications of using a stochastic thermostat have been discussed elsewhere. ${ }^{52}$ A 2 ns equilibration run and a 3 ns production run were performed. At least six independent trajectories each of length 5 ns are employed to 
attain good statistics.

The self-diffusivity in the axial direction is calculated by the Einstein relation:

$$
D_{\text {self }}=\lim _{t \rightarrow \infty} \frac{\left\langle\Delta z(t)^{2}\right\rangle}{2 t}
$$

where, $\left\langle\Delta z(t)^{2}\right\rangle$ denotes the mean-square displacement (MSD) of the particle in the axial direction. The single-component Maxwell-Stefan (MS) diffusivity in the axial direction is calculated by the Green-Kubo formula: ${ }^{53,54}$

$$
Ð=\frac{1}{N} \int_{0}^{\infty}\langle\mathbf{j}(0) \cdot \mathbf{j}(t)\rangle \mathrm{d} t
$$

where $\mathbf{j}(t)$ is the sum of the molecular velocities in the axial direction. Note that this expression can also be formulated in terms of the MD trajectory. ${ }^{54}$ The membrane selectivity $\alpha_{\text {perm, } \mathrm{CO}_{2} / \mathrm{CH}_{4}}$ of $\mathrm{CO}_{2}$ over $\mathrm{CH}_{4}$ is estimated by ${ }^{5}$

$$
\alpha_{\text {perm, } \mathrm{CO}_{2} / \mathrm{CH}_{4}}=\alpha_{\text {diff }} \alpha_{\text {sorp }}=\frac{D_{\mathrm{CO}_{2}, \text { self }}\left(x_{\mathrm{CO}_{2}}, x_{\mathrm{CH}_{4}}\right)}{D_{\mathrm{CH}_{4}, \text { self }}\left(x_{\mathrm{CO}_{2}}, x_{\mathrm{CH}_{4}}\right)} \frac{x_{\mathrm{CO}_{2}} / x_{\mathrm{CH}_{4}}}{y_{\mathrm{CO}_{2}} / y_{\mathrm{CH}_{4}}},
$$

where $\alpha_{\text {sorp }}$ and $\alpha_{\text {diff }}$ are the sorption and diffusion selectivities, respectively. $D_{\mathrm{CO}_{2} \text {, self }}$ and $D_{\mathrm{CH}_{4} \text {,self }}$ are the self-diffusivities of $\mathrm{CO}_{2}$ and $\mathrm{CH}_{4}$, respectively. $x_{\mathrm{CO}_{2}}\left(y_{\mathrm{CO}_{2}}\right)$ and $x_{\mathrm{CH}_{4}}\left(y_{\mathrm{CH}_{4}}\right)$ are the mole fractions of $\mathrm{CO}_{2}$ and $\mathrm{CH}_{4}$ in the adsorbed phase (bulk phase), respectively.

\section{Theoretical details}

The sorption isotherms of gas mixtures can be predicted based on the pure-component isotherms and the IAST. ${ }^{33,55-57}$ The IAST is an analogue of Raoult's law for vaporliquid equilibria and the pure-component isotherms must be fitted to a continuous function to allow the analytical or numerical solutions. More details can be found in our previous work. ${ }^{33}$ Here, we utilized the dual-site Langmuir model ${ }^{1,2}$ to fit our 
simulation data.

Results of the pure-component systems obtained from molecular simulations allowed good predictions of the binary mixture transport in nanoporous systems. $1,3,4,25,58$ According to Krishna and Paschek (KP), ${ }^{58}$ the single-component self-diffusivity $D_{i \text {,self }}$ of species $i$ and the MS diffusivity $\bigoplus_{i}$ are related by the following equation:

$$
D_{i, \mathrm{self}}=\frac{1}{\frac{1}{D_{i}}+\frac{\theta_{i}}{D_{i i}^{\text {corr }}}}
$$

where $\theta_{i}$ is the fractional loading defined as $\Theta_{i} / \Theta_{i, \text { sat }}\left(\Theta_{i}\right.$ and $\Theta_{i, \text { sat }}$ are the loading of species $i$ and the saturation loading of species $i$, respectively), and $\bigoplus_{i i}^{\text {corr }}$ is the selfexchange coefficient. The self-diffusivity $D_{i \text {,self }}$ of species $i$ in the mixture is given $\operatorname{as}^{58}$

$$
D_{i, \text { self }}=\frac{1}{\frac{1}{\emptyset_{i}}+\frac{\theta_{i}}{\emptyset_{i i}^{\text {corr }}}+\frac{\theta_{j}}{\bigoplus_{i j}^{\text {corr }}}}
$$

where $\bigoplus_{i j}^{\text {corr }}$ is the binary-exchange coefficient. These parameters can be obtained using the pure-component sorption and diffusion data, and the interpolation formula for the exchange coefficients proposed by Skoulidas et al.: ${ }^{1}$

$$
\Theta_{j, \mathrm{sat}} \bigoplus_{i j}^{\mathrm{corr}}=\left[\Theta_{j, \mathrm{sat}} \bigoplus_{i i}^{\mathrm{corr}}\right]^{\Theta_{i} /\left(\Theta_{i}+\Theta_{j}\right)}\left[\Theta_{i, \mathrm{sat}} \bigoplus_{j j}^{\mathrm{corr}}\right]^{\Theta_{j} /\left(\Theta_{i}+\Theta_{j}\right)}=\Theta_{i, \mathrm{sat}} \bigoplus_{j i}^{\mathrm{corr}}
$$

\section{Results and discussion}

\subsection{Methane and carbon dioxide in CNT arrays with pread- sorbed water}

\subsubsection{Adsorption properties}

We carried out GCMC simulations to calculate the pure-component adsorption isotherms for $\mathrm{CH}_{4}$ and $\mathrm{CO}_{2}$ in CNTs containing variable amounts of preadsorbed water at $300 \mathrm{~K}$. Fig. 2 provides the simulated isotherms (symbols) for the $(7,7),(10,10)$, and $(15,15)$ 
nanotubes up to pressures of 40 bar. Note that the total uptake of $\mathrm{CH}_{4}$ and $\mathrm{CO}_{2}$ is reported, unless otherwise noted. Fig. 2 also shows the best fits (lines) of the simulation data to the dual-site Langmuir model. These fits are necessary for modelling of the isotherm curves of the gas mixtures using the IAST (see below). Furthermore, our simulation results are in good agreement with previous simulation studies ${ }^{18,19}$ (see, e.g., Figure S1, Supporting Information). From Figure S1, it is seen that the simulation results are consistent with the experimental observations. ${ }^{13}$ Notably, the difference between the GCMC and experimental results has been discussed in detail and may be attributed to factors such as impurities in the experimental samples. ${ }^{15}$ Typically, the experimental measurements yield the excess adsorption isotherms. Figures S2 and S3 show the accessible pore volume (estimated using the GCMC simulation of helium adsorption in CNTs) and the excess adsorption isotherms for all studied systems, respectively. We see that the total and excess quantities are almost identical under these conditions.

Our results show that the adsorption of $\mathrm{CH}_{4}$ and $\mathrm{CO}_{2}$ in the CNTs generally increases with increasing nanotube diameter. Note that at low pressures, a high uptake of $\mathrm{CH}_{4}$ and $\mathrm{CO}_{2}$ is obtained in relatively small pores. The present results are in good agreement with the previous simulation studies. ${ }^{18-21,27}$ The enhancement in the adsorption of methane and carbon dioxide in small pores of CNTs can be attributed to the fluid-solid interaction. ${ }^{18-21}$ Similar enhancements have been observed in systems such as clays ${ }^{33}$ and carbon slit nanopores. ${ }^{59,60}$ We also see that the adsorption of $\mathrm{CH}_{4}$ and $\mathrm{CO}_{2}$ in the CNTs generally decreases with increasing water content. At low pressures, the presence of $\mathrm{H}_{2} \mathrm{O}$ enhances the adsorption of $\mathrm{CO}_{2}$ in CNTs with large diameters. These results are consistent with the previous simulation studies. ${ }^{22-24}$ The enhancement in the adsorption of carbon dioxide in CNTs can be attributed to the $\mathrm{CO}_{2}$-water interaction. ${ }^{22,23}$ A similar enhancement has been observed in systems such as MOFs, ${ }^{61}$ clays, ${ }^{33}$ and carbon slit nanopores. ${ }^{62}$ We note that, in all cases except for the dry $(15,15)$ nanotube at low pressures, the adsorption in the interstitial spaces is less than about $10 \%$ of the total adsorption (Figure S4). The changes in the intertube distance 
can significantly affect the gas adsorption properties in CNTs. ${ }^{18,63-65}$ For example, the $\mathrm{CO}_{2}$ adsorption was found to display a nonlinear behavior as a function of intertube distance. ${ }^{64}$ It was also found that the adsorption of methane and $\mathrm{CO}_{2}$ in the CNTs decreases with the increase of temperature. ${ }^{18,23,66}$

The density distributions of the various species in the CNTs can be readily obtained from our molecular simulations. Fig. 3 shows the density profiles (radial) of the different species in the $(7,7)$ nanotube at $P=0.1$ bar. Figures S5-S15 show these profiles in the other cases. Our results show that one, two, and three layers of water molecules are formed in the $(7,7),(10,10)$, and $(15,15)$ nanotubes, respectively, at all water contents. The water density profiles are almost unaffected by the presence of methane and $\mathrm{CO}_{2}$ under the studied conditions. We see that similar well-defined layered structures are also observed in the cases of methane and $\mathrm{CO}_{2}$ molecules. Each peak position in the distribution of methane and $\mathrm{CO}_{2}$ molecules almost coincides with that of the water region. The peak magnitude and/or the number of layers of methane and $\mathrm{CO}_{2}$ molecules in the CNTs generally increase with increasing pressure. The layered structures are formed probably because initially molecules adsorb at highaffinity adsorption sites on the CNT surface and the second layer, for example, is further induced by the high molecular density in the first layer. ${ }^{18-21,27}$ Furthermore, we observe a uniform distribution of each species in a circular path around the pore center (see, e.g., Figures S16-S18). It is known ${ }^{22-24}$ that the water molecules form strong hydrogen-bonded clusters, however, in the axial direction of the CNTs (see, e.g., Figure S19).

It is observed that $\mathrm{CO}_{2}$ molecules near the surface prefer to orient parallel to the nanotube axis (see, e.g., Figure S20), which is in line with the previous report. ${ }^{23}$ For example, in all cases, the angle between the molecular axis and the nanotube axis $(\alpha)$ is about $43{ }^{\circ} \mathrm{C}$ in the layer close to the surface. Note that in the absence of curvature, $\mathrm{CO}_{2}$ molecules are oriented more parallel to the slit surface. ${ }^{67}$ With the increasing nanotube diameter, the carbon dioxide molecules explore a wider range of angles. For instance, the orientation angle $\alpha$ is about $54^{\circ} \mathrm{C}$ in the center of the $(15,15)$ nanotube. 
In general, pressure has no effect on these orientations under the studied conditions. However, $\mathrm{CO}_{2}$ molecules in the center of the $(10,10)$ nanotube tend to lie more parallel to the nanotube axis as the pressure increases. These orientations are not much affected by the presence of water, probably because the water molecules form isolated clusters. We also find that the water dipoles tend to lie parallel to the nanotube axis in the layer close to the surface (see, e.g., Figures S21-S24). The presence of $\mathrm{CH}_{4}$ and $\mathrm{CO}_{2}$ has less effect on the orientation of water.

The adsorption equilibrium can also be characterized by the isosteric heat of adsorption. Figure S25 shows the isosteric heats of adsorption of methane and $\mathrm{CO}_{2}$ in the CNTs calculated from GCMC simulations. The isosteric heats of adsorption of methane and $\mathrm{CO}_{2}$ are in the ranges of about $15-35 \mathrm{~kJ} / \mathrm{mol}$ and $20-40 \mathrm{~kJ} / \mathrm{mol}$, respectively, under the studied conditions. In general, the isosteric heats of adsorption of methane and $\mathrm{CO}_{2}$ decrease with increasing nanotube diameter. This may be due to the fact that the fluid-solid interaction is dominant in the small pores. We also see that the isosteric heats generally increase with increasing $\mathrm{CH}_{4} / \mathrm{CO}_{2}$ loading and increasing water content. This increase is possibly due to the fluid-fluid interaction. However, in the small pores, the isosteric heats decrease with loading because adsorption of molecules at sites further from the surface leads to lower fluid-solid interaction. This behavior is also observed for the large pores at low loadings, which can be attributed to the adsorption in the interstitial region. These results are consistent with previous studies. ${ }^{18,23,27}$

\subsubsection{Transport properties}

The GCMC generated configurations were used in the MD simulations to calculate the transport properties of methane, $\mathrm{CO}_{2}$, and water in the CNTs. Figures S26-S28 shows some typical MSDs as a function of the simulation time. Three regimes are generally observed in the plot of the MSD versus time for particles under confinement. An initial ballistic regime and the long-time Fickian regime are separated by an intermediate single-file diffusion regime. ${ }^{68,69}$ Single-file diffusion is the restricted motion 
of species that cannot pass each other. The self-diffusion coefficients were calculated from the linear slopes in the plot of the MSD versus time. Fig. 4 shows the simulated self-diffusivity (symbols) of $\mathrm{CH}_{4}$ and $\mathrm{CO}_{2}$ in CNTs containing variable amounts of preadsorbed water at $300 \mathrm{~K}$. Figure S29 shows the corresponding self-diffusivity of water under the studied conditions.

Our results show that the mobility of $\mathrm{CH}_{4}$ and $\mathrm{CO}_{2}$ generally increases with increasing nanotube diameter. Also, for a given diameter, the mobility of $\mathrm{CH}_{4}$ and $\mathrm{CO}_{2}$ in the CNTs decreases with increasing $\mathrm{CH}_{4} / \mathrm{CO}_{2}$ loading and increasing water content. This decrease with $\mathrm{CH}_{4} / \mathrm{CO}_{2}$ loading is less pronounced at higher water contents. These results may be attributed to the steric interactions. We find that, at a constant loading, the $\mathrm{CH}_{4}$ molecules diffuse faster than the $\mathrm{CO}_{2}$ molecules in the dry CNTs. Furthermore, the effect of the preadsorbed water is more pronounced on the mobility of methane than that of $\mathrm{CO}_{2}$. This may be explained by the fact that the $\mathrm{H}_{2} \mathrm{O}$ molecules form isolated clusters along the axial direction (see, e.g., Figure S19) and that such formation is more favorable for $\mathrm{CH}_{4}$ than for carbon dioxide because of the fact that the $\mathrm{CH}_{4}-\mathrm{H}_{2} \mathrm{O}$ interaction is weaker than the carbon dioxide- $\mathrm{H}_{2} \mathrm{O}$ interaction. Similar behavior has been reported in the carbon slit pores. ${ }^{62}$ Notably at high water contents, we see that the mobility of methane is a nonmonotonic function of the nanotube diameter. This is possibly due to the stability of the large water clusters, especially in the large pores (see, e.g., Figure S19). The splitting of such clusters in the small pores may lead to a faster diffusion process. Also our analysis based on the breadth-first search algorithm ${ }^{23}$ for these systems shows that a splitting of the large water cluster occurs mainly in the $(7,7)$ nanotube at all pressures and water contents. A similar behavior was reported for water in CNTs. ${ }^{70}$ However, this anomalous diffusion behavior was attributed to the formation of the ice-like structure of water. We see that the water mobility generally decreases with increasing nanotube diameter and increasing water content. This is again attributed to the presence of water clusters. Also, the water mobility generally decrease with $\mathrm{CH}_{4} / \mathrm{CO}_{2}$ loading, and the mobility of water associated with $\mathrm{CO}_{2}$ is relatively low possibly because of the stronger water- $\mathrm{CO}_{2}$ interaction. 
Our results are in good agreement with the previous simulation studies. ${ }^{7,19,24,25}$

Fig. 4 also shows the predictions (lines) of the expression relating $D_{i, \text { self }}$ to $\bigoplus_{i}$ derived by Krishna and Paschek (see eq. (5)). ${ }^{58}$ For simplicity, the self-exchange coefficient $\bigoplus_{i i}^{\text {corr }}$ is assumed to be $\mathrm{CH}_{4} / \mathrm{CO}_{2}$ loading-independent and used as the fitting parameter. These fits are necessary for the calculations of the mixture transport using the KP approach (see below). Figure S30 shows the MS diffusivities of $\mathrm{CH}_{4}$ and $\mathrm{CO}_{2}$ in the CNTs. Notably, the MS diffusivities of $\mathrm{CH}_{4}$ and $\mathrm{CO}_{2}$ are almost independent of loading. We also note that at high water contents and/or low loadings, the above approach is less reliable when using a loading-independent $\bigoplus_{i i}^{\text {corr }}$ (see, e.g., Figure S31).

\subsection{Methane/carbon dioxide mixture in CNT arrays with pread- sorbed water}

\subsubsection{Adsorption properties}

We also performed GCMC simulations to calculate the adsorption isotherms for the mixture of $\mathrm{CH}_{4}$ and $\mathrm{CO}_{2}$ in CNTs containing variable amounts of preadsorbed water at 300 K. Fig. 5 provides the simulated isotherms (symbols) for the $(7,7),(10,10)$, and $(15,15)$ nanotubes up to pressures of 40 bar. In addition, the adsorption isotherms of the mixture are estimated by applying the $\mathrm{IAST}^{55}$ to the pure-component adsorption isotherms (see Fig. 2) and provided as smooth lines in Fig. 5. Our simulation results are in good qualitative agreement with the IAST data over the investigated pressure range. The difference is possibly because of the fact that the IAST fails to describe the adsorption isotherms for nonideal mixtures and/or high pressures. ${ }^{33,71}$ We see that the overall adsorption behavior of the mixture is similar to that observed for the purecomponent adsorption isotherms, as described above. Notably, at low pressures, a high uptake of $\mathrm{CH}_{4}$ and $\mathrm{CO}_{2}$ is obtained in relatively small pores and the presence of $\mathrm{H}_{2} \mathrm{O}$ enhances the adsorption of $\mathrm{CO}_{2}$ in CNTs with large diameters. As expected, the adsorption isotherms obtained using an equimolar mixture of $\mathrm{CH}_{4}$ and $\mathrm{CO}_{2}$ show that the CNTs preferentially adsorb $\mathrm{CO}_{2}$ over $\mathrm{CH}_{4}$ both in the absence and presence 
of preadsorbed water. Our results are in good agreement with the previous simulation studies. ${ }^{20,22,26,27}$

The gas separation processes can be adjusted by tuning the adsorption selectivities (see eq. (4)). ${ }^{5}$ The adsorption selectivity of $\mathrm{CO}_{2} / \mathrm{CH}_{4}$ calculated using the GCMC simulations (symbols) and the IAST (lines) are shown in Figure S32. The adsorption selectivity of $\mathrm{CO}_{2} / \mathrm{CH}_{4}$ is in the range of about $3-100$ under the studied conditions. Our results show that the adsorption selectivity of $\mathrm{CO}_{2} / \mathrm{CH}_{4}$ generally decreases with increasing mole fraction $y_{\mathrm{CH}_{4}}$ and increasing nanotube diameter. Also, the adsorption selectivity of $\mathrm{CO}_{2} / \mathrm{CH}_{4}$ generally increases with pressure. This may be attributed to the fluid-fluid interaction. ${ }^{20,22}$ For example, the increase in the $\mathrm{CO}_{2}$-adsorbate interaction energy was found to be greater than that of the $\mathrm{CH}_{4}$-adsorbate interaction energy. ${ }^{20}$ However, at very high pressures, the entropic effects may be important and the adsorption selectivity decreases with pressure. ${ }^{27}$ Also, at low pressures, the adsorption selectivity of $\mathrm{CO}_{2} / \mathrm{CH}_{4}$ decreases with pressure in the $(15,15)$ nanotube. This may be attributed to the species adsorption in the interstitial region and consequently, the enhanced adsorbate-adsorbent interactions. ${ }^{27}$ A similar decrease was also observed for the $(6,6)$ nanotube case. ${ }^{27}$ In the absence of the interstitial region, the adsorption selectivity of $\mathrm{CO}_{2} / \mathrm{CH}_{4}$ increased with pressure. ${ }^{20}$ It is important to note that the adsorption selectivity of $\mathrm{CO}_{2} / \mathrm{CH}_{4}$ increases with water content. This may be because of the relatively stronger water- $\mathrm{CO}_{2}$ interactions. ${ }^{22}$ Here, the overall density distributions of the various species (see, e.g., Figures S33-S35) and their orientations (see, e.g., Figures S36-S40) in the CNTs are similar to those observed for the $\mathrm{CH}_{4} / \mathrm{H}_{2} \mathrm{O}$ and $\mathrm{CO}_{2} / \mathrm{H}_{2} \mathrm{O}$ mixtures in CNTs, as described above. Notably, each peak position in the distributions of methane and $\mathrm{CO}_{2}$ molecules almost coincides with that of the water region. We also see that water molecules form isolated clusters in the axial direction of the CNTs (see, e.g., Figure S41). 


\subsubsection{Transport properties}

The GCMC generated configurations of the $\mathrm{CH}_{4} / \mathrm{CO}_{2} / \mathrm{H}_{2} \mathrm{O}$ mixture in CNTs were used in the MD simulations to calculate the transport properties of this system. Fig. 6 shows the simulated self-diffusivity (symbols) of $\mathrm{CH}_{4}$ and $\mathrm{CO}_{2}$ in this system at 300

$\mathrm{K}$. In addition, these diffusivities are estimated by applying the KP approach ${ }^{1,58}$ to the diffusion data of the $\mathrm{CH}_{4} / \mathrm{H}_{2} \mathrm{O}$ and $\mathrm{CO}_{2} / \mathrm{H}_{2} \mathrm{O}$ mixtures in CNTs (see Fig. 4) and provided as smooth lines in Fig. 6. In the past, the KP approach has been successfully applied to many ordered nanoporous systems. ${ }^{1-4,25,58}$ Our simulation results are in qualitative agreement with the KP predictions (see eq. (6)). The difference at high water contents and/or low loadings is possibly because of the use of the $\mathrm{CH}_{4} / \mathrm{CO}_{2}$ loading-independent $\bigoplus_{i i}^{\text {corr }}$. Note that the treatment of the loading dependence of $\bigoplus_{i i}^{\text {corr }}$ in the KP approach is nontrivial. ${ }^{1,25}$ We see that the overall diffusion behavior of the $\mathrm{CH}_{4} / \mathrm{CO}_{2} / \mathrm{H}_{2} \mathrm{O}$ mixture in CNTs is similar to that observed for the $\mathrm{CH}_{4} / \mathrm{H}_{2} \mathrm{O}$ and $\mathrm{CO}_{2} / \mathrm{H}_{2} \mathrm{O}$ mixtures in CNTs, as described above (see also Figure S42). For example, the mobility of $\mathrm{CH}_{4}$ and $\mathrm{CO}_{2}$ in the CNTs decreases with increasing $\mathrm{CH}_{4} / \mathrm{CO}_{2}$ loading and increasing water content, and the effect of the preadsorbed water is more pronounced on the mobility of methane than that of $\mathrm{CO}_{2}$.

An important finding of this study is that at constant $\mathrm{CH}_{4}$ loading and constant water content, the mobility of $\mathrm{CH}_{4}$ in the CNTs decreases with decreasing mole fraction $y_{\mathrm{CH}_{4}}$. In general, this decrease is more pronounced at higher loadings of $\mathrm{CH}_{4}$ and lower water contents. However, the presence of $\mathrm{CH}_{4}$ has less effect on the diffusion properties of $\mathrm{CO}_{2}$ in the CNTs. These results may be explained by the preferential adsorption of $\mathrm{CO}_{2}$ over $\mathrm{CH}_{4}$ in the CNTs, as is evident from the adsorption results presented above. Since $\mathrm{CO}_{2}$ molecules are the dominant adsorbed species, their distribution in the CNTs are not much affected by the presence of $\mathrm{CH}_{4}$. Due to this, the mobility of $\mathrm{CO}_{2}$ is mostly independent of the mole fraction $y_{\mathrm{CH}_{4}}$. As shown above, carbon dioxide molecules preferentially adsorb onto the surface and consequently screen those adsorption sites from their direct interaction with methane, which may lead to an increased 
mobility of methane. At the same time, $\mathrm{CO}_{2}$ molecules occupy also the pore region away from the surface because of which the effective diffusing space of methane may be reduced. Both of these effects are important at low adsorbate loadings and lead to a small decrease in the methane mobility. At high loadings, however, the steric factors dominate resulting in a significant reduction in the methane mobility. Similar observations were reported for the diffusion behavior of $\mathrm{CH}_{4}$ and $\mathrm{CO}_{2}$ in montmorillonite clays. ${ }^{34}$ However, an opposite trend was observed in the case of ZIFs due to the difference in the adsorption site preferences. ${ }^{6}$ It is interesting to note that the $\mathrm{CH}_{4} / \mathrm{H}_{2}$ mixture diffusivities are governed by the momentum transfer correlation effects which tend to reduce the mobility of the faster diffusing molecules and speed up the slower molecules. ${ }^{6}$ Interestingly, at low loadings, a non-monotonic behavior has been observed in our simulations for the species diffusion as a function of loading, e.g., for $\mathrm{CO}_{2}$ in the dry $(15,15)$ nanotube arrays. This may be due to the species adsorption in the interstitial region as mentioned above, and the relatively slow species diffusion in the sterically confined interstitial spaces.

The gas separation processes can be adjusted also by tuning the diffusion selectivities (see eq. (4)). ${ }^{5}$ The diffusion selectivity of $\mathrm{CO}_{2} / \mathrm{CH}_{4}$ calculated using the molecular simulations (symbols) and the KP predictions (lines) are shown in Figure S43. The diffusion selectivity of $\mathrm{CO}_{2} / \mathrm{CH}_{4}$ is in the range of about $0.2-2$ for the considered systems. We see that the diffusion selectivity of $\mathrm{CO}_{2} / \mathrm{CH}_{4}$ increases with decreasing nanotube diameter and increasing water content for the studied systems. Also, the diffusion selectivity is almost independent of the pressure and the mole fraction $y_{\mathrm{CH}_{4}}$ for the studied systems.

For gas storage and separation, the membrane selectivity is an important performance metric (see eq. (4)). ${ }^{5}$ The membrane selectivity of $\mathrm{CO}_{2} / \mathrm{CH}_{4}$ calculated using the molecular simulations (symbols) and the predictions based on the IAST and the $\mathrm{KP}$ approach (lines) are shown in Fig. $7\left(y_{\mathrm{CH}_{4}}=0.8\right)$. Figures $\mathrm{S} 44$ and $\mathrm{S} 45$ provide the results for the cases of $y_{\mathrm{CH}_{4}}=0.2$ and $y_{\mathrm{CH}_{4}}=0.5$, respectively. Note that the adsorption selectivity of $\mathrm{CO}_{2} / \mathrm{CH}_{4}$ is in the range of about $3-9$ for the considered sys- 
tems. Our results show that the membrane selectivity of $\mathrm{CO}_{2} / \mathrm{CH}_{4}$ generally increases with increasing pressure and increasing water content. However, at low pressures, the membrane selectivity of $\mathrm{CO}_{2} / \mathrm{CH}_{4}$ decreases with pressure in the $(15,15)$ nanotube. This may be attributed to the species adsorption in the interstitial region, as described above. Also, the membrane selectivity generally decreases with increasing nanotube diameter and is almost independent of the mole fraction $y_{\mathrm{CH}_{4}}$ for the considered systems. Overall, our results indicate that the adsorption properties are the dominant factor determining the separation of the $\mathrm{CH}_{4} / \mathrm{CO}_{2}$ mixture in both dry and wet CNTs.

Note that we used the self-diffusivities for the determination of the membrane selectivities. In reality the collective behavior may be important for gas transport properties. It is known that the transport diffusivities of, e.g., $\mathrm{CO}_{2}$ in the CNTs are almost independent of pressure. ${ }^{19}$ However, since the membrane selectivity is dominated by the adsorption process, the general conclusions drawn here are not expected to be altered significantly. Note also that the adsorption selectivity of $\mathrm{CO}_{2} / \mathrm{CH}_{4}$ predicted using the 5-site model of methane was higher than that obtained using the 1-site model by a factor of about 1.5 at all pressures. ${ }^{20}$ Also, the activation energies of translational diffusion for the 5-site model of methane were slightly lower than those for the 1-site model. ${ }^{72}$ Furthermore, modifying CNTs with functional groups and the incorporation of CNTs in a polymer matrix are attractive for applications in the gas separation processes. ${ }^{16,73,74}$ For example, $\mathrm{H}_{2}$ was found to be more selective for $\mathrm{CNT} /$ polymer nanocomposites in comparison to $\mathrm{N}_{2}$ and $\mathrm{CO}_{2} \cdot{ }^{73}$ The nature of these effects will be discussed in detail in a future publication.

\section{Conclusions}

Molecular simulations were carried out to study the adsorption and diffusion properties of $\mathrm{CH}_{4}$ and $\mathrm{CO}_{2}$ in single-walled CNT arrays with preadsorbed water at $300 \mathrm{~K}$ and pressures up to 40 bar. Our results show that, at low pressures, a high uptake of $\mathrm{CH}_{4}$ and $\mathrm{CO}_{2}$ is obtained in relatively small pores, which can be attributed to the fluid-solid 
interaction. ${ }^{18-23}$ At low pressures, the presence of $\mathrm{H}_{2} \mathrm{O}$ enhances the adsorption of $\mathrm{CO}_{2}$ in CNTs with large diameters. This enhancement can be attributed to the $\mathrm{CO}_{2}$-water interaction. We find that the $\mathrm{CH}_{4}$ molecules diffuse faster than the $\mathrm{CO}_{2}$ molecules in the dry CNTs, consistent with previous studies. ${ }^{7,19,24,25}$ Furthermore, the effect of the preadsorbed water is more pronounced on the mobility of $\mathrm{CH}_{4}$ than that of $\mathrm{CO}_{2}$. This may be explained by the fact that the $\mathrm{H}_{2} \mathrm{O}$ molecules form strong hydrogen-bonded clusters along the axial direction of the CNTs and that such formation is more favorable for $\mathrm{CH}_{4}$ than for $\mathrm{CO}_{2}$. Interestingly, at high water contents, we find that the mobility of $\mathrm{CH}_{4}$ is a nonmonotonic function of the nanotube diameter. This is possibly due to the splitting of the water clusters in the small pores which may lead to a faster diffusion process.

Molecular simulations were also carried out for the $\mathrm{CH}_{4} / \mathrm{CO}_{2}$ mixture in CNTs with preadsorbed water at $300 \mathrm{~K}$. Here, the overall adsorption and diffusion properties are similar to those observed for the $\mathrm{CH}_{4} / \mathrm{H}_{2} \mathrm{O}$ and $\mathrm{CO}_{2} / \mathrm{H}_{2} \mathrm{O}$ mixtures in CNTs. The adsorption selectivity of $\mathrm{CO}_{2} / \mathrm{CH}_{4}$ generally increases with pressure, which may be attributed to the fluid-fluid interaction. ${ }^{20,22,26,27}$ Also, the adsorption selectivity increases with water content. This may be because of the relatively stronger water$\mathrm{CO}_{2}$ interactions. An important finding of this study is that the mobility of $\mathrm{CH}_{4}$ in the CNTs decreases with decreasing mole fraction $y_{\mathrm{CH}_{4}}$. In general, this decrease is more pronounced at higher loadings of $\mathrm{CH}_{4}$ and lower water contents. However, the presence of $\mathrm{CH}_{4}$ has less effect on the diffusion properties of $\mathrm{CO}_{2}$ in the CNTs. These results may be explained by the preferential adsorption of $\mathrm{CO}_{2}$ over $\mathrm{CH}_{4}$ in the CNTs. Furthermore, these simulated adsorption isotherms and diffusivity data were compared to the theoretical predictions based on the IAST and the KP approach, respectively. The simulation results are in reasonable agreement with the theoretical predictions.

\section{Acknowledgments}

This publication is based upon work supported by the King Abdullah University of Science and Technology (KAUST) Office of Sponsored Research (OSR) under Award 
No. OSR-2019-CRG8-4074. Y.Y. and A.K.N.N. would like to thank computational support from KAUST.

\section{Supporting Information}

Additional details of simulation analysis are provided in the Supporting Information. 


\section{References}

(1) Skoulidas, A. I.; Sholl, D. S.; Krishna, R. Correlation effects in diffusion of $\mathrm{CH} 4 / \mathrm{CF} 4$ mixtures in MFI zeolite. A study linking MD simulations with the Maxwell- Stefan formulation. Langmuir 2003, 19, 7977-7988

(2) Keskin, S.; Sholl, D. S. Screening metal- organic framework materials for membrane-based methane/carbon dioxide separations. The Journal of Physical Chemistry $C$ 2007, 111, 14055-14059

(3) Keskin, S.; Liu, J.; Johnson, J. K.; Sholl, D. S. Testing the accuracy of correlations for multicomponent mass transport of adsorbed gases in metal- organic frameworks: diffusion of H2/CH4 mixtures in CuBTC. Langmuir 2008, 24, 8254-8261

(4) Jee, S. E.; Sholl, D. S. Carbon dioxide and methane transport in DDR zeolite: insights from molecular simulations into carbon dioxide separations in small pore zeolites. Journal of the American Chemical Society 2009, 131, 7896-7904

(5) Keskin, S.; Sholl, D. S. Efficient methods for screening of metal organic framework membranes for gas separations using atomically detailed models. Langmuir 2009, 25, 11786-11795

(6) Liu, J.; Keskin, S.; Sholl, D. S.; Johnson, J. K. Molecular simulations and theoretical predictions for adsorption and diffusion of $\mathrm{CH} 4 / \mathrm{H} 2$ and $\mathrm{CO} 2 / \mathrm{CH} 4$ mixtures in ZIFs. The Journal of Physical Chemistry C 2011, 115, 12560-12566

(7) Cao, W.; Tow, G. M.; Lu, L.; Huang, L.; Lu, X. Diffusion of CO2/CH4 confined in narrow carbon nanotube bundles. Molecular Physics 2016, 114, 2530-2540

(8) Robeson, L. M. The upper bound revisited. Journal of membrane science 2008, 320, 390-400

(9) Sumida, K.; Rogow, D. L.; Mason, J. A.; McDonald, T. M.; Bloch, E. D.; 
Herm, Z. R.; Bae, T.-H.; Long, J. R. Carbon dioxide capture in metal-organic frameworks. Chemical reviews 2012, 112, 724-781

(10) Martin, R. L.; Simon, C. M.; Smit, B.; Haranczyk, M. In silico design of porous polymer networks: high-throughput screening for methane storage materials. Journal of the American Chemical Society 2014, 136, 5006-5022

(11) Thornton, A. W.; Simon, C. M.; Kim, J.; Kwon, O.; Deeg, K. S.; Konstas, K.; Pas, S. J.; Hill, M. R.; Winkler, D. A.; Haranczyk, M., et al. Materials genome in action: identifying the performance limits of physical hydrogen storage. Chemistry of Materials 2017, 29, 2844-2854

(12) Cinke, M.; Li, J.; Bauschlicher Jr, C. W.; Ricca, A.; Meyyappan, M. CO2 adsorption in single-walled carbon nanotubes. Chemical Physics Letters 2003, 376, $761-766$

(13) Kleinhammes, A.; Mao, S.-H.; Yang, X.-J.; Tang, X.-P.; Shimoda, H.; Lu, J.; Zhou, O.; Wu, Y. Gas adsorption in single-walled carbon nanotubes studied by NMR. Physical Review B 2003, 68, 075418

(14) Lu, C.; Bai, H.; Wu, B.; Su, F.; Hwang, J. F. Comparative study of CO2 capture by carbon nanotubes, activated carbons, and zeolites. Energy $\&$ Fuels 2008, 22, $3050-3056$

(15) Lithoxoos, G. P.; Labropoulos, A.; Peristeras, L. D.; Kanellopoulos, N.; Samios, J.; Economou, I. G. Adsorption of N2, CH4, CO and CO2 gases in single walled carbon nanotubes: A combined experimental and Monte Carlo molecular simulation study. The Journal of Supercritical Fluids 2010, 55, 510-523

(16) Sears, K.; Dumée, L.; Schütz, J.; She, M.; Huynh, C.; Hawkins, S.; Duke, M.; Gray, S. Recent developments in carbon nanotube membranes for water purification and gas separation. Materials 2010, 3, 127-149 
(17) Su, F.; Lu, C.; Cnen, W.; Bai, H.; Hwang, J. F. Capture of CO2 from flue gas via multiwalled carbon nanotubes. Science of the total environment 2009, 40\%, $3017-3023$

(18) Mahdizadeh, S. J.; Tayyari, S. F. Influence of temperature, pressure, nanotube's diameter and intertube distance on methane adsorption in homogeneous armchair open-ended SWCNT triangular arrays. Theoretical Chemistry Accounts 2011, $128,231-240$

(19) Skoulidas, A. I.; Sholl, D. S.; Johnson, J. K. Adsorption and diffusion of carbon dioxide and nitrogen through single-walled carbon nanotube membranes. The Journal of chemical physics 2006, 124, 054708

(20) Liu, L.; Nicholson, D.; Bhatia, S. K. Adsorption of CH4 and CH4/CO2 mixtures in carbon nanotubes and disordered carbons: A molecular simulation study. Chemical Engineering Science 2015, 121, 268-278

(21) Cao, D.; Zhang, X.; Chen, J.; Wang, W.; Yun, J. Optimization of single-walled carbon nanotube arrays for methane storage at room temperature. The Journal of Physical Chemistry B 2003, 10\%, 13286-13292

(22) Liu, L.; Nicholson, D.; Bhatia, S. K. Impact of H2O on CO2 separation from natural gas: comparison of carbon nanotubes and disordered carbon. The Journal of Physical Chemistry C 2015, 119, 407-419

(23) Liu, L.; Bhatia, S. K. Molecular simulation of CO2 adsorption in the presence of water in single-walled carbon nanotubes. The Journal of Physical Chemistry C 2013, 117, 13479-13491

(24) Liu, L.; Hu, C.; Nicholson, D.; Bhatia, S. K. Inhibitory effect of adsorbed water on the transport of methane in Carbon nanotubes. Langmuir 2017, 33, 6280-6291

(25) Krishna, R.; Van Baten, J. Describing binary mixture diffusion in carbon nanotubes with the Maxwell- Stefan equations. An investigation using molecular dy- 
namics simulations. Industrial $\&$ engineering chemistry research 2006, 45, 20842093

(26) Huang, L.; Zhang, L.; Shao, Q.; Lu, L.; Lu, X.; Jiang, S.; Shen, W. Simulations of binary mixture adsorption of carbon dioxide and methane in carbon nanotubes: temperature, pressure, and pore size effects. The Journal of Physical Chemistry C 2007, 111, 11912-11920

(27) Palmer, J. C.; Moore, J. D.; Roussel, T. J.; Brennan, J. K.; Gubbins, K. E. Adsorptive behavior of $\mathrm{CO} 2, \mathrm{CH} 4$ and their mixtures in carbon nanospace: a molecular simulation study. Physical Chemistry Chemical Physics 2011, 13, $3985-3996$

(28) Kumar, N. A.; Seidel, C. Polyelectrolyte brushes with added salt. Macromolecules 2005, 38, 9341-9350

(29) Kumar, N. A.; Ganesan, V. Communication: Self-assembly of semiflexible-flexible block copolymers. 2012

(30) Stukalin, E. B.; Cai, L.-H.; Kumar, N. A.; Leibler, L.; Rubinstein, M. Self-healing of unentangled polymer networks with reversible bonds. Macromolecules 2013, $46,7525-7541$

(31) Narayanan Nair, A. K.; Martinez Jimenez, A.; Sun, S. Complexation behavior of polyelectrolytes and polyampholytes. The Journal of Physical Chemistry B 2017, 121, $7987-7998$

(32) Choudhary, N.; Nair, A. K. N.; Ruslan, M. F. A. C.; Sun, S. Bulk and interfacial properties of decane in the presence of carbon dioxide, methane, and their mixture. Scientific Reports 2019, 9, 1-10

(33) Kadoura, A.; Nair, A. K. N.; Sun, S. Adsorption of carbon dioxide, methane, and their mixture by montmorillonite in the presence of water. Microporous and Mesoporous Materials 2016, 225, 331-341 
(34) Kadoura, A.; Narayanan Nair, A. K.; Sun, S. Molecular dynamics simulations of carbon dioxide, methane, and their mixture in montmorillonite clay hydrates. The Journal of Physical Chemistry C 2016, 120, 12517-12529

(35) Kadoura, A.; Narayanan Nair, A. K.; Sun, S. Molecular simulation study of montmorillonite in contact with variably wet supercritical carbon dioxide. The Journal of Physical Chemistry C 2017, 121, 6199-6208

(36) Yang, Y.; Narayanan Nair, A. K.; Sun, S. Molecular dynamics simulation study of carbon dioxide, methane, and their mixture in the presence of brine. The Journal of Physical Chemistry B 2017, 121, 9688-9698

(37) Yang, Y.; Narayanan Nair, A. K.; Sun, S. Layer Charge Effects on Adsorption and Diffusion of Water and Ions in Interlayers and on External Surfaces of Montmorillonite. ACS Earth and Space Chemistry 2019, 3, 2635-2645

(38) Yang, Y.; Che Ruslan, M. F. A.; Narayanan Nair, A. K.; Sun, S. Effect of ion valency on the properties of the carbon dioxide-methane-brine system. The Journal of Physical Chemistry B 2019, 123, 2719-2727

(39) Yang, Y.; Narayanan Nair, A. K.; Sun, S. Adsorption and diffusion of methane and carbon dioxide in amorphous regions of cross-linked polyethylene: a molecular simulation study. Industrial \&f Engineering Chemistry Research 2019, 58, 84268436

(40) Li, Y.; Narayanan Nair, A. K.; Kadoura, A.; Yang, Y.; Sun, S. Molecular simulation study of montmorillonite in contact with water. Industrial \&6 Engineering Chemistry Research 2019, 58, 1396-1403

(41) Yang, Y.; Narayanan Nair, A. K.; Sun, S. Sorption and diffusion of methane and carbon dioxide in amorphous poly (alkyl acrylates): a molecular simulation study. The Journal of Physical Chemistry B 2020, 124, 1301-1310 
(42) Dubbeldam, D.; Calero, S.; Ellis, D. E.; Snurr, R. Q. RASPA: molecular simulation software for adsorption and diffusion in flexible nanoporous materials. Molecular Simulation 2016, 42, 81-101

(43) Plimpton, S. Fast parallel algorithms for short-range molecular dynamics; 1993

(44) Steele, W. A. The interaction of rare gas atoms with graphitized carbon black. The Journal of Physical Chemistry 1978, 82, 817-821

(45) Berendsen, H.; Grigera, J.; Straatsma, T. The missing term in effective pair potentials. Journal of Physical Chemistry 1987, 91, 6269-6271

(46) Martin, M. G.; Siepmann, J. I. Transferable potentials for phase equilibria. 1. United-atom description of n-alkanes. The Journal of Physical Chemistry B 1998, 102, 2569-2577

(47) Harris, J. G.; Yung, K. H. Carbon dioxide's liquid-vapor coexistence curve and critical properties as predicted by a simple molecular model. The Journal of Physical Chemistry 1995, 99, 12021-12024

(48) Zhong, H.; Lai, S.; Wang, J.; Qiu, W.; LuÃ̂̃ËĘdemann, H.-D.; Chen, L. Molecular dynamics simulation of transport and structural properties of CO2 using different molecular models. Journal of Chemical \& Engineering Data 2015, 60, $2188-2196$

(49) Karavias, F.; Myers, A. L. Isosteric heats of multicomponent adsorption: thermodynamics and computer simulations. Langmuir 1991, 7, 3118-3126

(50) Peng, D.-Y.; Robinson, D. B. A new two-constant equation of state. Industrial \& Engineering Chemistry Fundamentals 1976, 15, 59-64

(51) Schneider, T.; Stoll, E. Molecular-dynamics study of a three-dimensional onecomponent model for distortive phase transitions. Physical Review B 1978, 17, 1302 
(52) Chen, Q.; Moore, J. D.; Liu, Y.-C.; Roussel, T. J.; Wang, Q.; Wu, T.; Gubbins, K. E. Transition from single-file to Fickian diffusion for binary mixtures in single-walled carbon nanotubes. The Journal of chemical physics 2010, 133, 094501

(53) Maginn, E. J.; Bell, A. T.; Theodorou, D. N. Transport diffusivity of methane in silicalite from equilibrium and nonequilibrium simulations. The Journal of Physical Chemistry 1993, 97, 4173-4181

(54) Theodorou, D.; Snurr, R.; Bell, A. Comprehensive Supramolecular Chemistry. Oxford: Pergamon 1996, 7, 507

(55) Myers, A. L.; Prausnitz, J. M. Thermodynamics of mixed-gas adsorption. AIChE journal 1965, 11, 121-127

(56) Do, D. D. Adsorption analysis: equilibria and kinetics; Imperial college press London, 1998; Vol. 2

(57) Simon, C. M.; Smit, B.; Haranczyk, M. pyIAST: Ideal adsorbed solution theory (IAST) Python package. Computer Physics Communications 2016, 200, 364-380

(58) Krishna, R.; Paschek, D. Self-diffusivities in multicomponent mixtures in zeolites. Physical Chemistry Chemical Physics 2002, 4, 1891-1898

(59) Kurniawan, Y.; Bhatia, S. K.; Rudolph, V. Simulation of binary mixture adsorption of methane and CO2 at supercritical conditions in carbons. AIChE journal 2006, 52, 957-967

(60) Zhou, J.; Wang, W. Adsorption and diffusion of supercritical carbon dioxide in slit pores. Langmuir 2000, 16, 8063-8070

(61) Yazaydın, A. O.; Benin, A. I.; Faheem, S. A.; Jakubczak, P.; Low, J. J.; Willis, R. R.; Snurr, R. Q. Enhanced CO2 adsorption in metal-organic frameworks 
via occupation of open-metal sites by coordinated water molecules. Chemistry of Materials 2009, 21, 1425-1430

(62) Billemont, P.; Coasne, B.; De Weireld, G. An experimental and molecular simulation study of the adsorption of carbon dioxide and methane in nanoporous carbons in the presence of water. Langmuir 2011, 27, 1015-1024

(63) Zhang, X.; Cao, D.; Chen, J. Hydrogen adsorption storage on single-walled carbon nanotube arrays by a combination of classical potential and density functional theory. The Journal of Physical Chemistry B 2003, 107, 4942-4950

(64) Rahimi, M.; Singh, J. K.; Babu, D. J.; Schneider, J. J.; Müller-Plathe, F. Understanding carbon dioxide adsorption in carbon nanotube arrays: molecular simulation and adsorption measurements. The Journal of Physical Chemistry C 2013, $117,13492-13501$

(65) Yang, Y.-B.; Hao, Q.; Müller-Plathe, F.; Böhm, M. C. Monte Carlo Simulations of SO2, H2S and CO2 Adsorption in Charged Single-Walled Carbon Nanotube Arrays. The Journal of Physical Chemistry C 2020,

(66) Zhu, X.; Zhao, Y.-P. Atomic mechanisms and equation of state of methane adsorption in carbon nanopores. The Journal of Physical Chemistry C 2014, 118, $17737-17744$

(67) Bhatia, S.; Tran, K.; Nguyen, T.; Nicholson, D. High-pressure adsorption capacity and structure of CO2 in carbon slit pores: theory and simulation. Langmuir 2004, 20, 9612-9620

(68) Striolo, A. The mechanism of water diffusion in narrow carbon nanotubes. Nano letters 2006, 6, 633-639

(69) Kukla, V.; Kornatowski, J.; Demuth, D.; Girnus, I.; Pfeifer, H.; Rees, L. V.; Schunk, S.; Unger, K. K.; Kärger, J. NMR studies of single-file diffusion in unidimensional channel zeolites. Science 1996, 272, 702-704 
(70) Barati Farimani, A.; Aluru, N. R. Spatial diffusion of water in carbon nanotubes: from fickian to ballistic motion. The Journal of Physical Chemistry B 2011, 115, $12145-12149$

(71) Rahimi, M.; Singh, J. K.; Müller-Plathe, F. Adsorption and separation of binary and ternary mixtures of SO 2, CO 2 and N 2 by ordered carbon nanotube arrays: grand-canonical Monte Carlo simulations. Physical Chemistry Chemical Physics 2016, 18, 4112-4120

(72) Bartus, K.; Brodka, A. Temperature study of structure and dynamics of methane in carbon nanotubes. The Journal of Physical Chemistry C 2014, 118, 1201012016

(73) Sharma, A.; Tripathi, B.; Vijay, Y. K. Dramatic improvement in properties of magnetically aligned CNT/polymer nanocomposites. Journal of Membrane Science 2010, 361, 89-95

(74) Li, Y.; He, G.; Wang, S.; Yu, S.; Pan, F.; Wu, H.; Jiang, Z. Recent advances in the fabrication of advanced composite membranes. Journal of Materials Chemistry A 2013, 1, 10058-10077 


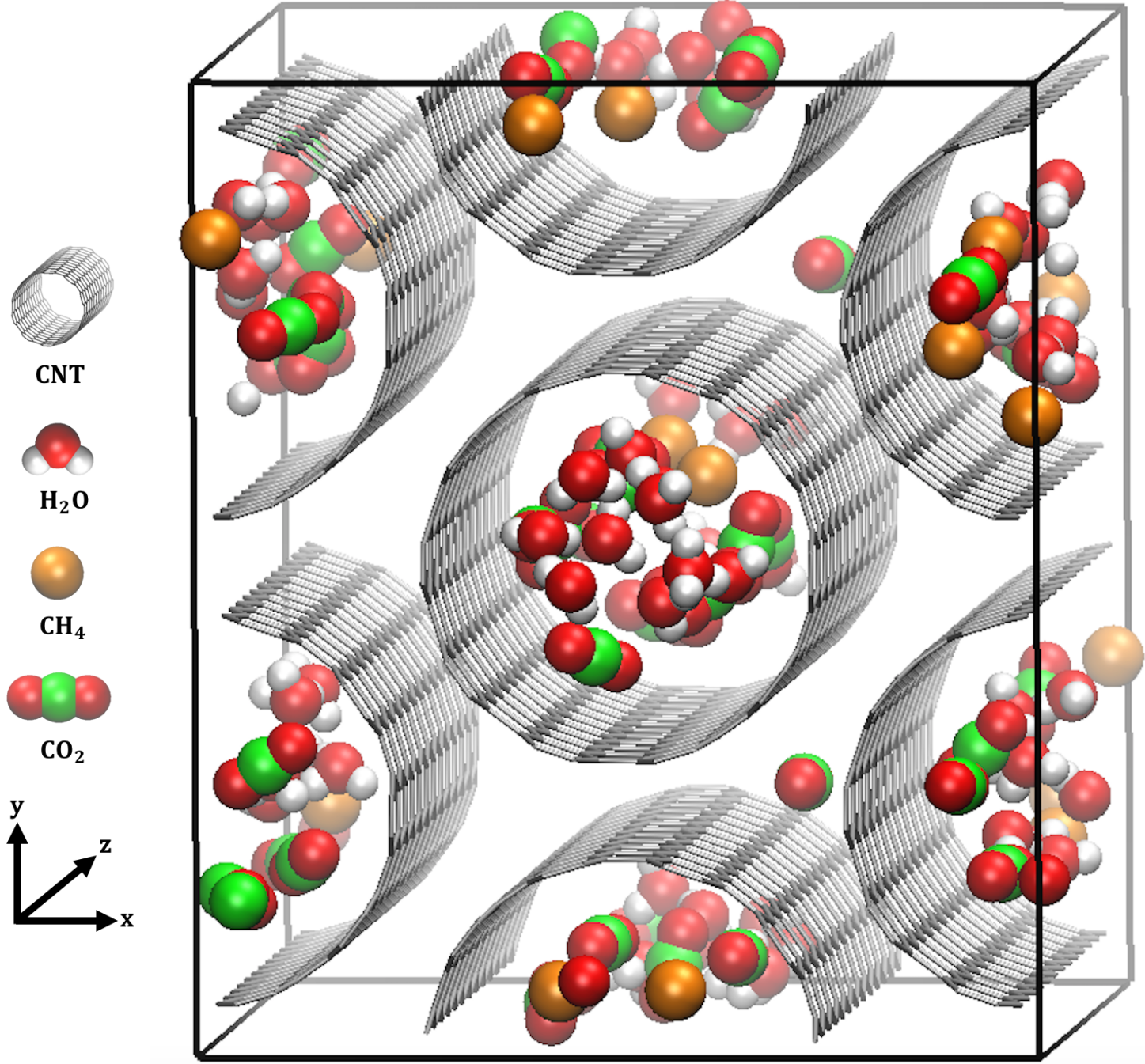

Figure 1: Equilibrium snapshot of the CNT arrays with a preadsorbed water content of $0.1 \mathrm{~g} / \mathrm{cm}^{3}$ and in contact with equimolar $\mathrm{CH}_{4} / \mathrm{CO}_{2}$ mixture at $300 \mathrm{~K}$ and 1 bar. The nanotube diameter is $1.356 \mathrm{~nm}((10,10)$ nanotube). 

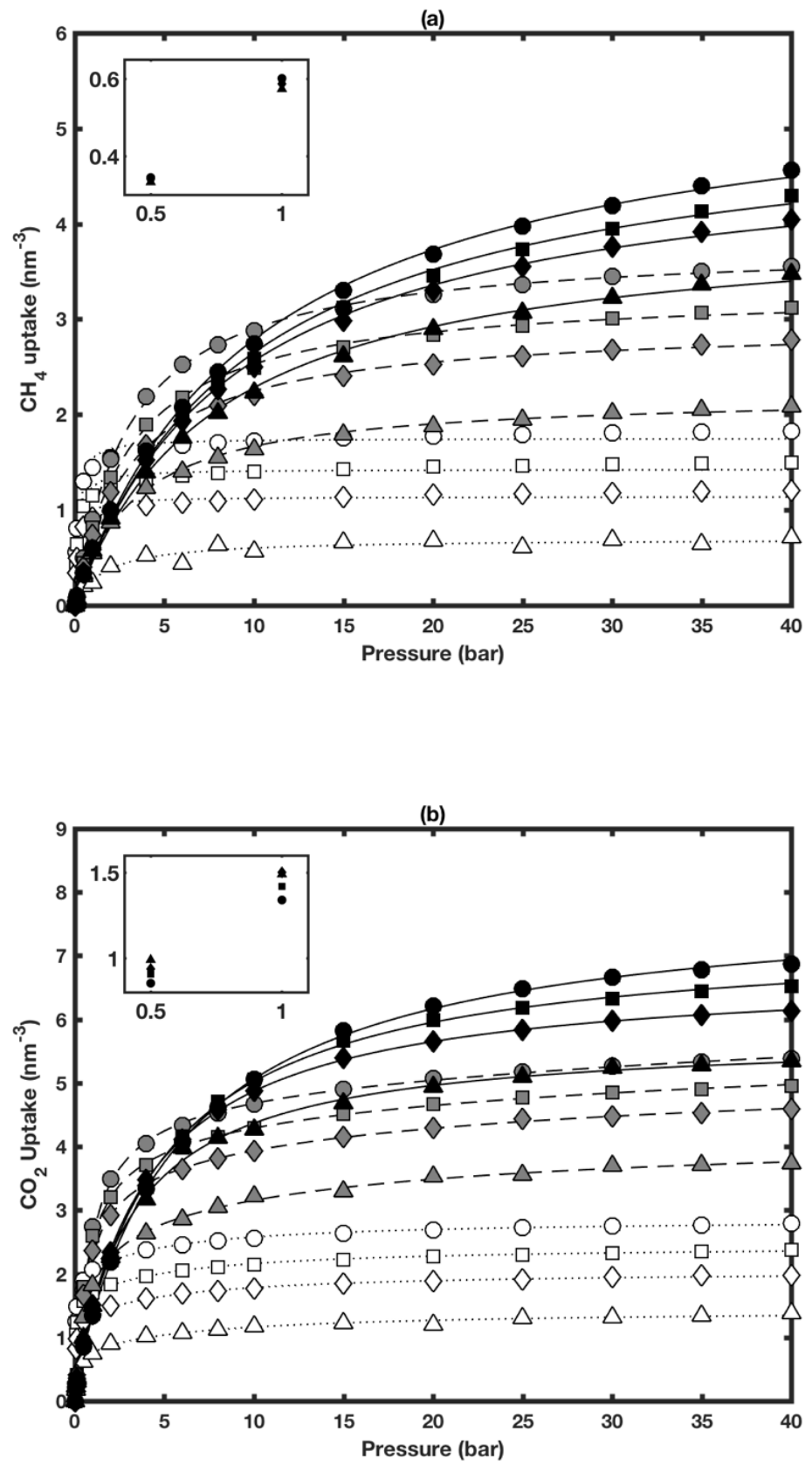

Figure 2: GCMC simulated pure-component adsorption isotherms for (a) $\mathrm{CH}_{4}$ and (b) $\mathrm{CO}_{2}$ molecules in the $(7,7)$ (open symbols), $(10,10)$ (gray-filled symbols), and $(15,15)$ (black-filled symbols) nanotubes with different amounts of preadsorbed water: 0 (circles), 0.05 (squares), 0.1 (diamonds), and $0.2 \mathrm{~g} / \mathrm{cm}^{3}$ (triangles). The temperature is $300 \mathrm{~K}$. The lines are fitting results to the GCMC simulation data. Inset: magnified view of the main figure at low pressures. 
(a)

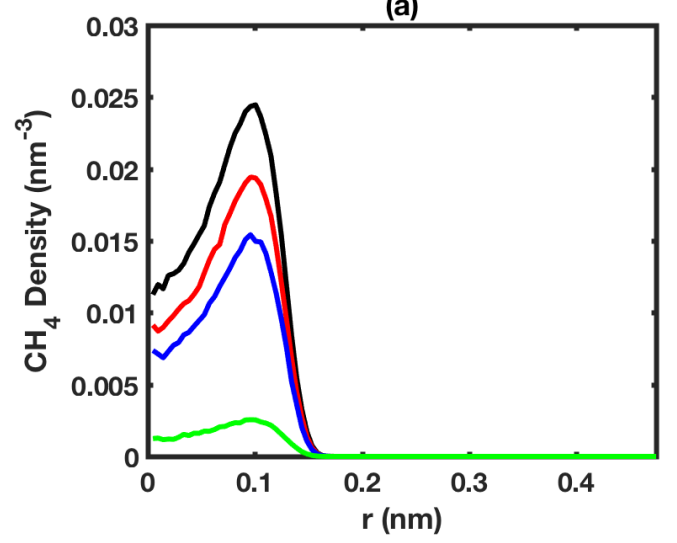

(b)

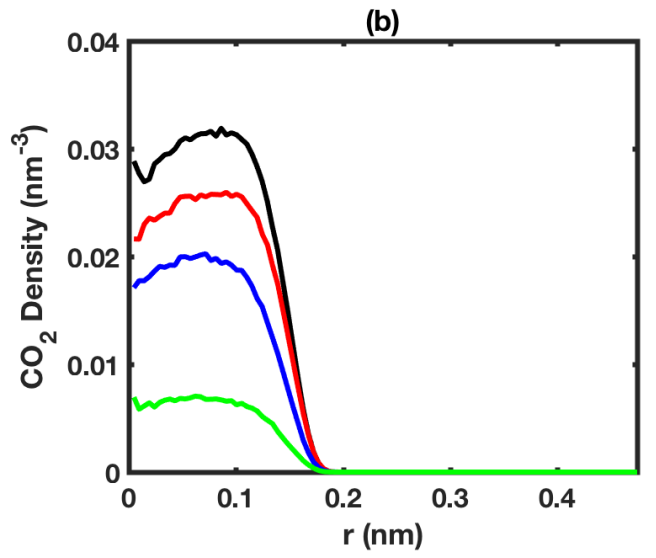

(c)

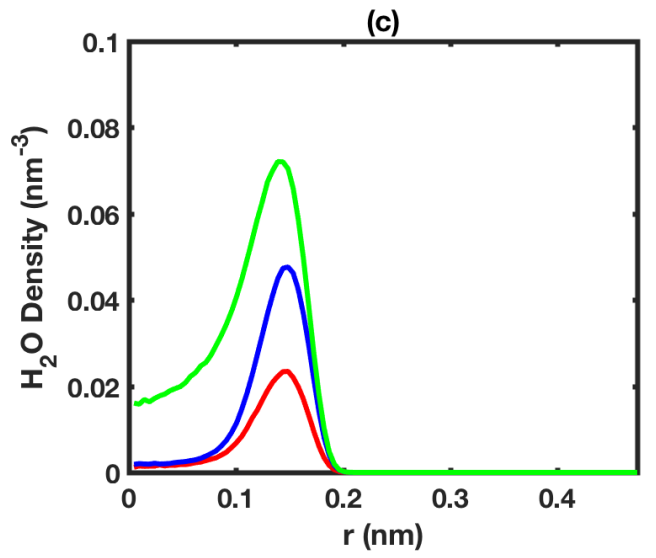

(d)

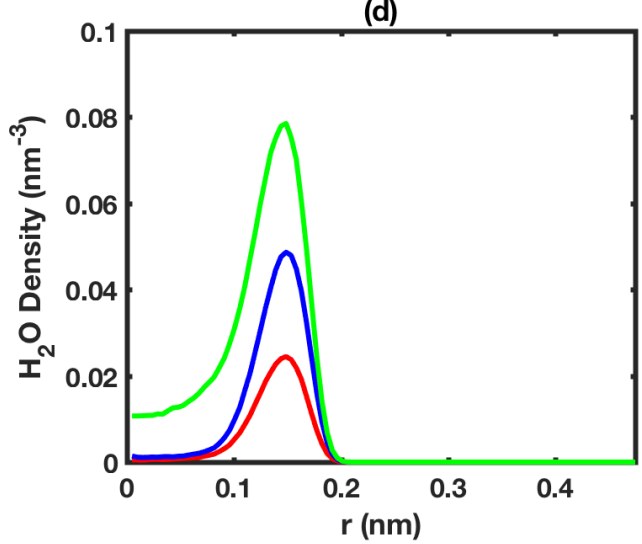

Figure 3: Radial density distributions of (a) $\mathrm{CH}_{4}$ and (b) $\mathrm{CO}_{2}$ molecules in the $(7,7)$ nanotube with different amounts of preadsorbed water: 0 (black lines), 0.05 (red lines), 0.1 (blue lines), and $0.2 \mathrm{~g} / \mathrm{cm}^{3}$ (green lines). The distributions of water corresponding to (a) and (b) are shown in (c) and (d), respectively. The temperature is $300 \mathrm{~K}$ and the pressure is 0.1 bar. The origin corresponds to the CNT center. 

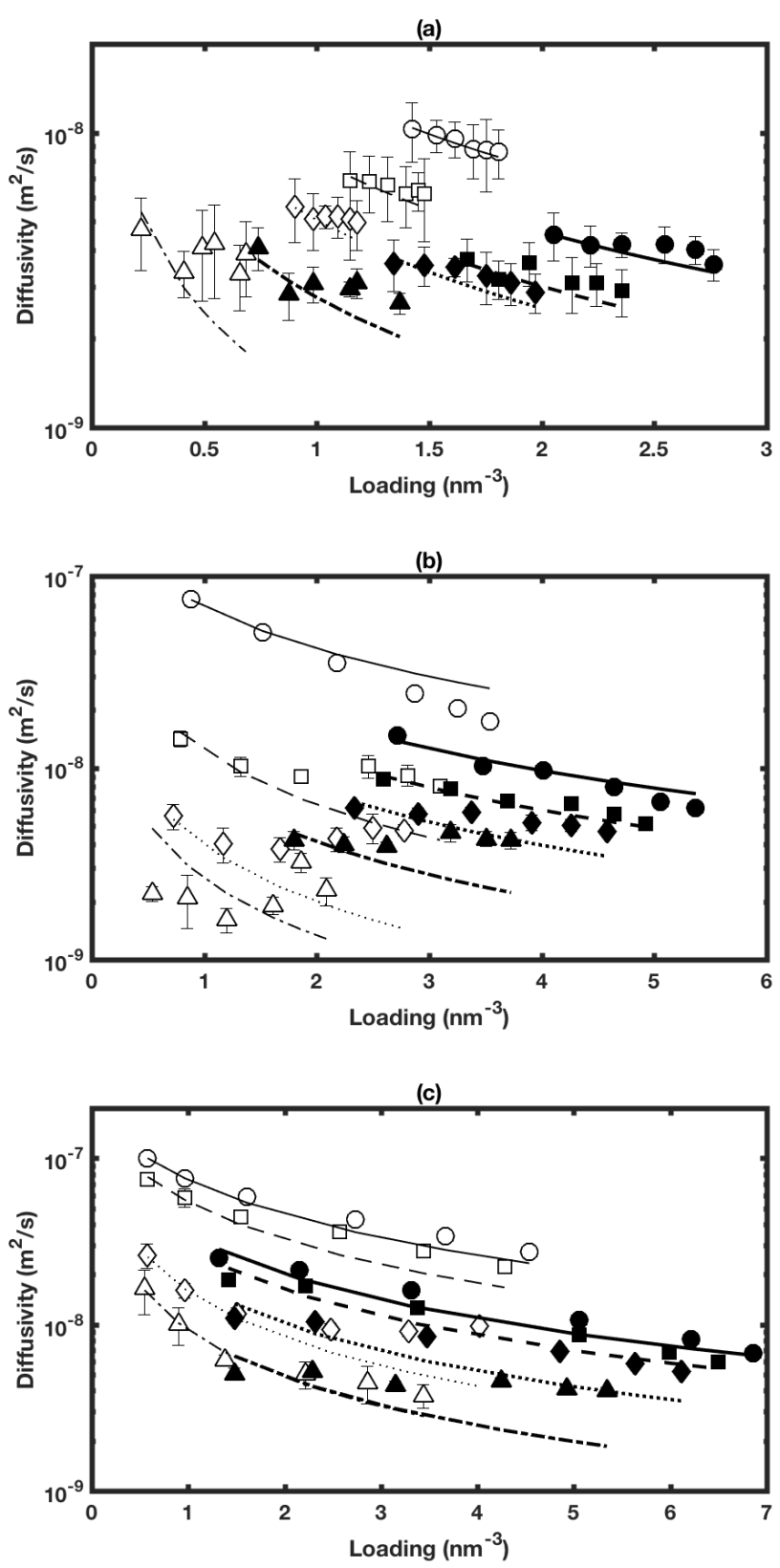

Figure 4: Self-diffusivities of $\mathrm{CH}_{4}$ (open symbols) and $\mathrm{CO}_{2}$ (solid symbols) molecules in the $(\mathrm{a})(7,7)$, (b) $(10,10)$, and (c) $(15,15)$ nanotubes with different amounts of preadsorbed water (0 (circles), 0.05 (squares), 0.1 (diamonds), and $0.2 \mathrm{~g} / \mathrm{cm}^{3}$ (triangles)), as obtained from MD simulations. The temperature is $300 \mathrm{~K}$. The lines are fitting results to the MD simulation data. 

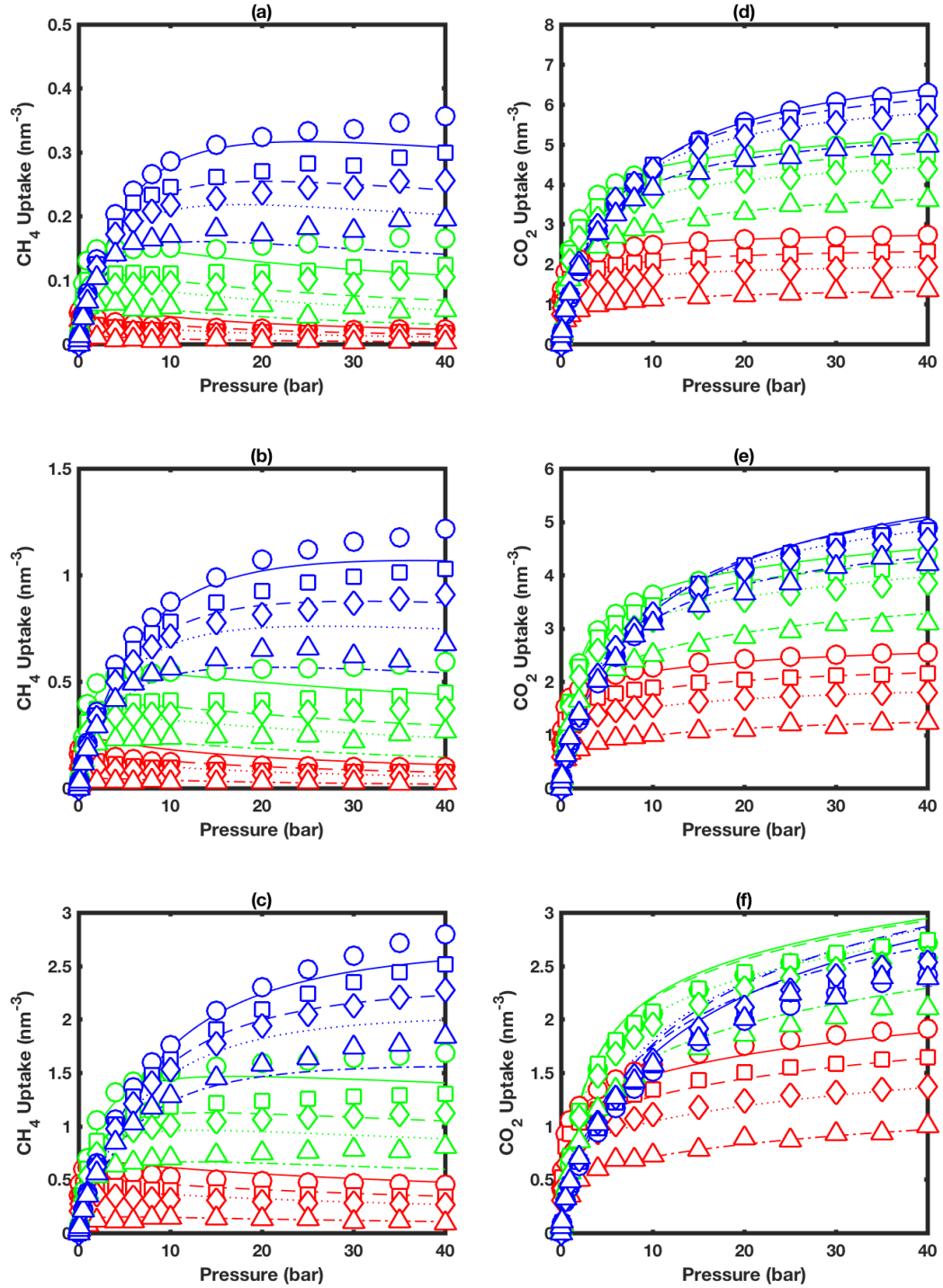

Figure 5: GCMC simulated adsorption isotherms for the $\mathrm{CH}_{4} / \mathrm{CO}_{2}$ mixture in the $(7,7)$ (red symbols), $(10,10)$ (green symbols), and $(15,15)$ (blue symbols) nanotubes with different amounts of preadsorbed water: 0 (circles), 0.05 (squares), 0.1 (diamonds), and $0.2 \mathrm{~g} / \mathrm{cm}^{3}$ (triangles). (a), (b), and (c) show adsorption isotherms of $\mathrm{CH}_{4}$ at mole fraction $y_{\mathrm{CH}_{4}}=0.2,0.5$, and 0.8 , respectively. (d), (e), and (f) show adsorption isotherms of $\mathrm{CO}_{2}$ at mole fraction $y_{\mathrm{CH}_{4}}=0.2,0.5$, and 0.8 , respectively. The temperature is 300 $\mathrm{K}$. The lines are the predictions of the IAST. 

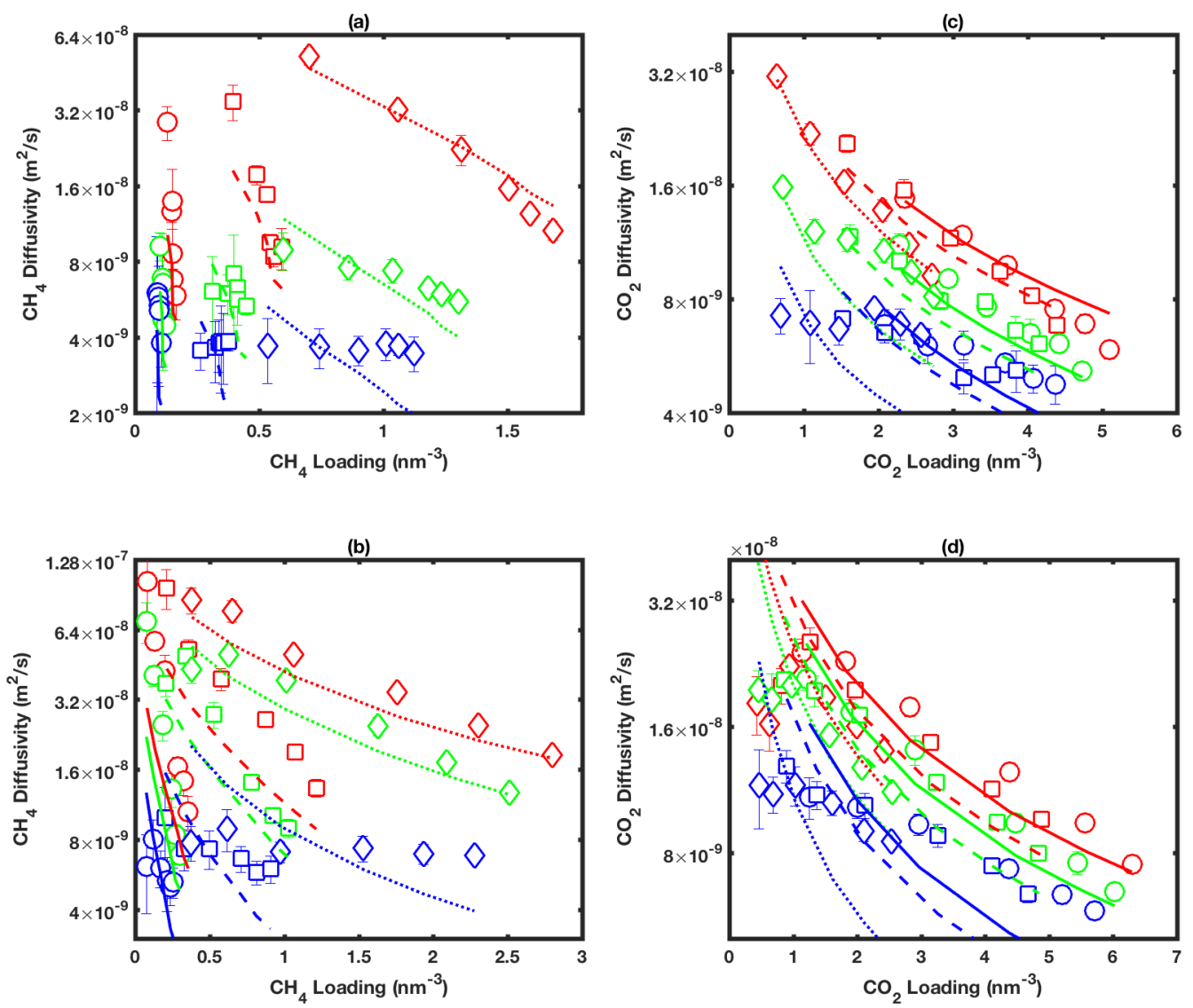

Figure 6: Self-diffusivities for the $\mathrm{CH}_{4} / \mathrm{CO}_{2}$ mixture $\left(y_{\mathrm{CH}_{4}}=0.2\right.$ (circles), 0.5 (squares), and 0.8 (diamonds)) in the nanotubes with different amounts of preadsorbed water (0 (red symbols), 0.05 (green symbols), and $0.1 \mathrm{~g} / \mathrm{cm}^{3}$ (blue symbols)), as obtained from MD simulations. (a) and (b) show self-diffusivities of $\mathrm{CH}_{4}$ in the $(10,10)$ and $(15,15)$ nanotubes, respectively. (c) and (d) show self-diffusivities of $\mathrm{CO}_{2}$ in the $(10,10)$ and $(15,15)$ nanotubes, respectively. The temperature is $300 \mathrm{~K}$. The lines are the predictions of the KP approach. 
(a)

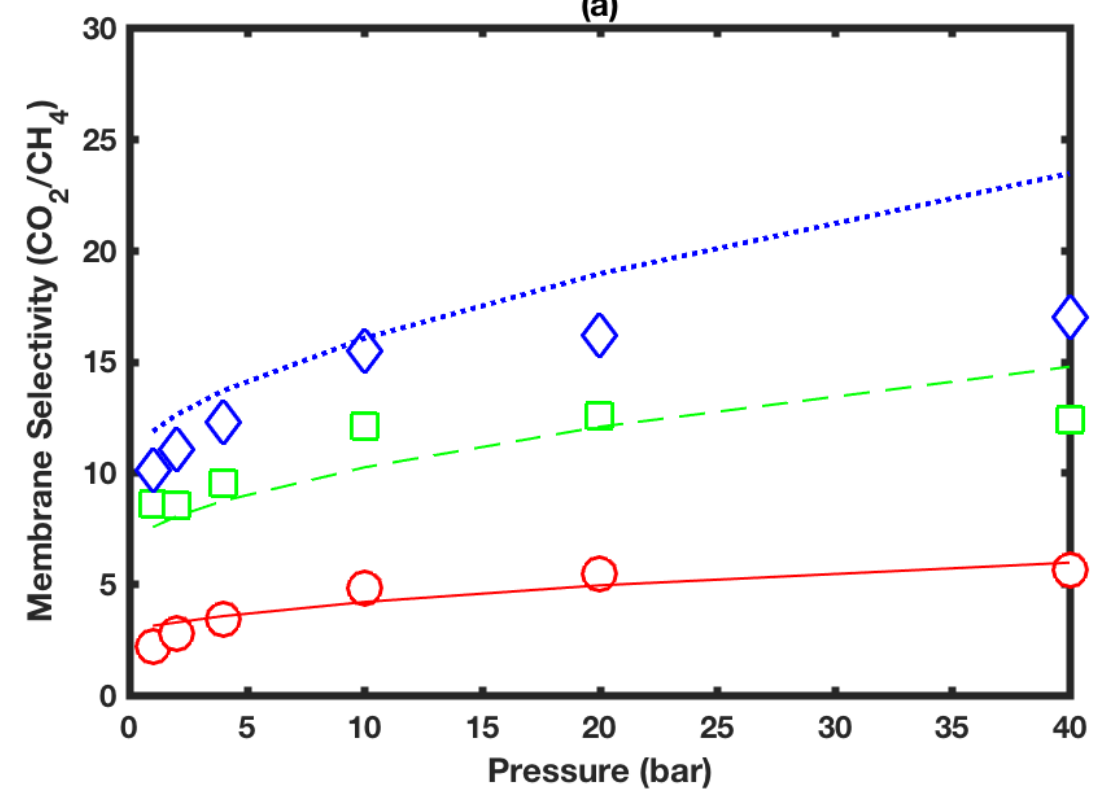

(b)

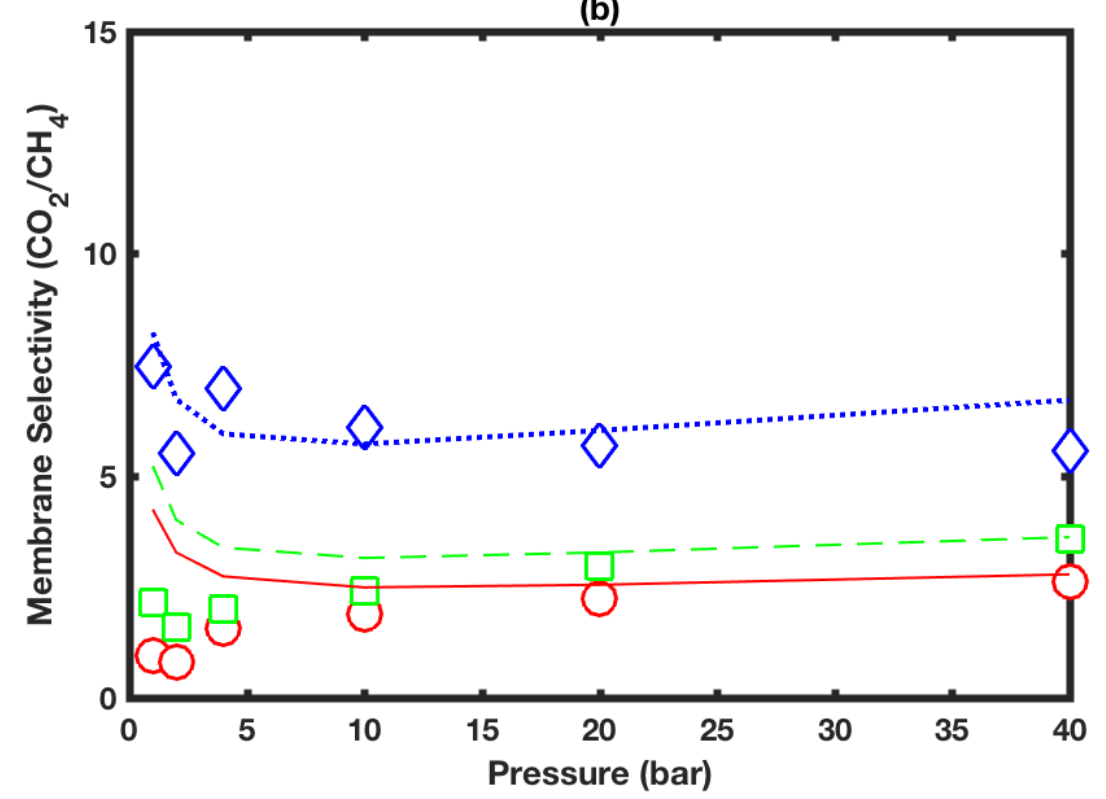

Figure 7: Membrane selectivity of $\mathrm{CO}_{2} / \mathrm{CH}_{4}\left(y_{\mathrm{CH}_{4}}=0.8\right)$ in the (a) $(10,10)$ and (b) $(15,15)$ nanotubes with different amounts of preadsorbed water: 0 (red symbols), 0.05 (green symbols), and $0.1 \mathrm{~g} / \mathrm{cm}^{3}$ (blue symbols). The temperature is $300 \mathrm{~K}$. The lines are the predictions based on the IAST and the KP approach. 


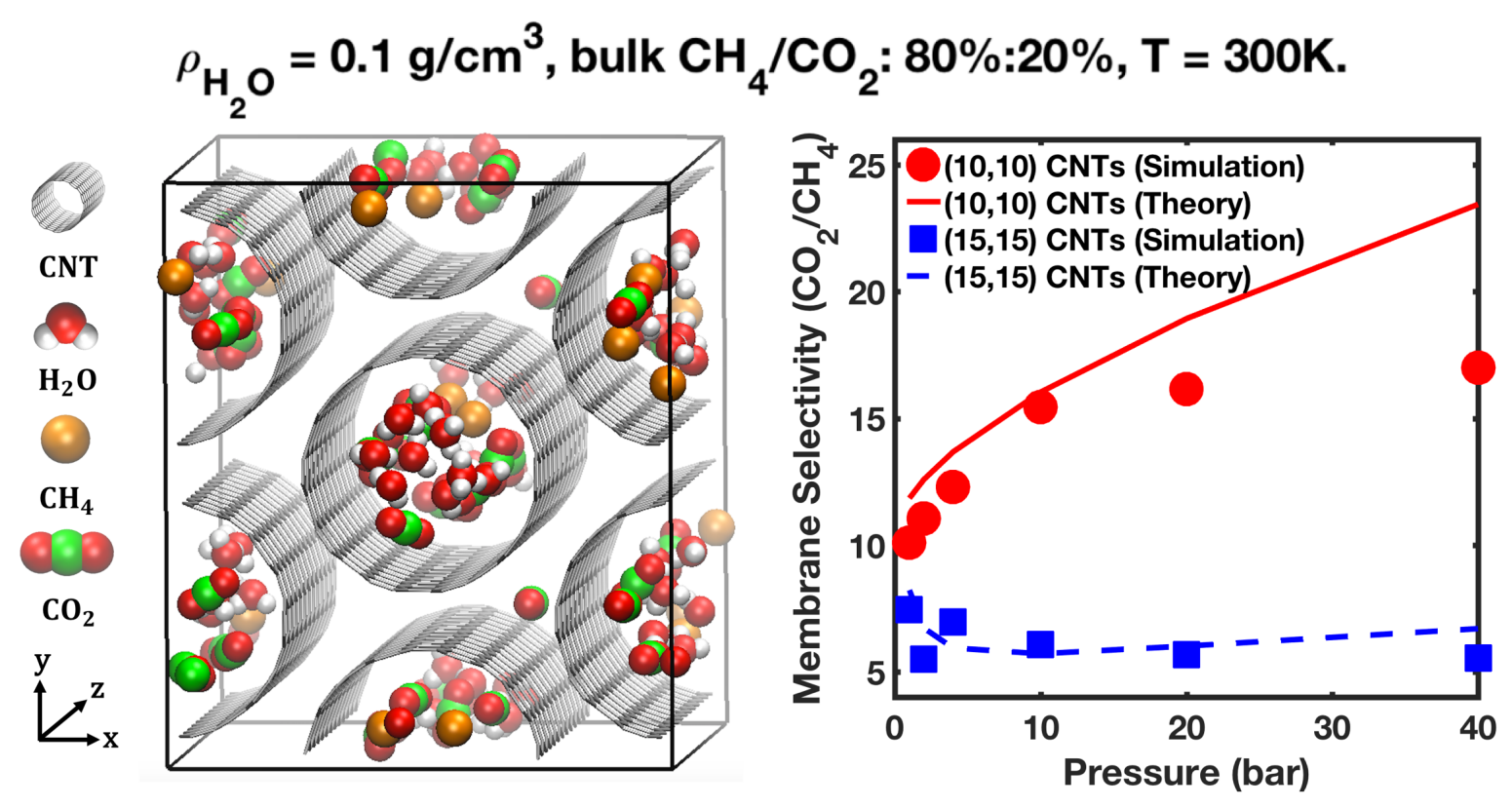

TOC Graphic 